\title{
A Novel Two-Quadrant Zero-Voltage Transition Converter for DC Motor Drives
}

\author{
K.T. Chau, T.W. Ching, C.C. Chan, and David T.W. Chan* \\ Department of Electrical and Electronic Engineering, \\ The University of Hong Kong, Pokfulam, HONG KONG \\ *Department of Electrical and Communications Engineering, \\ Hong Kong Technical College, Tsing Yi, HONG KONG
}

\begin{abstract}
A novel zero-voltage-transition (ZVT) two-quadrant (2Q) converter for dc motor drives is presented. It possesses the definite advantage that both main transistors and rectifiers can operate with zero-voltage switching in both motoring and regenerating modes, while both of these switches are only subjected to unity voltage and current stresses, namely the same as its PWM counterparts. This converter is particularly useful for dc traction systems in which both motoring and regenerative braking are desired to have high efficiency. The corresponding theoretical analysis and its high-efficiency performance are supported by both simulation and experimental results.
\end{abstract}

\section{INTRODUCTION}

Nowadays, the use of low-inductance dc motors is becoming attractive because of the advantages of higher power density, lower rotor inertia, smoother commutation and lower manufacturing costs. However, it usually suffers from high current ripples, resulting in increased losses and switching stresses. To alleviate this problem, the switching frequency of power converters needs to be increased from less than one to over one hundred kilohertz. With available power devices technologies, hard-switching PWM converters operating at such high frequencies impose high switching losses and switching stresses.

Recently, - number of soft-switching techniques, providing zero-voltage switching (ZVS) or zero-current switching (ZCS) conditions, have been successfully developed for switched-mode power supplies (SMPS) [1][4]. Surprisingly, the development of soft-switching converters for dc motor drives has been very little. Even so, it has been assumed that those being developed for SMPS can be directly applicable [5]. Until recently, a systematic evaluation of available soft-switching converters for $\mathrm{dc}$ motor drives has been carried out [6]. As a result, these softswitching converters cannot satisfy the operating requirements of dc motor drives. Apart from suffering excessive voltage and current stresses, they cannot handle bidirectional power flow during regenerative braking.

Different to SMPS, dc motor drives, especially in traction applications, needs regenerative braking. Technically, the $\mathrm{dc}$ motor operates as a generator to convert the kinetic energy into the electrical energy while the converter must allow for bidirectional power flow to restore the energy to the power networks or battery systems. This energy-recovery feature is particularly attractive to electric railways and battery-powered electric vehicles.

In this paper, a novel ZVS-PWM, so-called zero-voltage transition (ZVT), 2Q converter for de motor drives is proposed. Its principle of operation, characteristics curves in both the motoring and regenerative modes, design example, as well as simulation and experimental results will be given.

\section{PRINCIPLE OF OPERATION}

Fig. I shows the circuit diagram of the proposed ZVT-2Q soft-switching converter for dc motor drives. It differs from a conventional PWM-2Q converter, since the addition of a resonant inductor $\mathrm{Lr}$, a resonant capacitor $\mathrm{Cr}$ and two auxiliary switches $\mathrm{Sa}$ and $\mathrm{Sa}$.

Since the operating characteristics of the proposed converter are generally dictated by those resonant elements, the corresponding characteristics impedance $Z$ and angular frequency $\omega$ are defined as:

$Z=\sqrt{\frac{\mathrm{Lr}}{\mathrm{Cr}}}$
$\omega=\sqrt{\frac{1}{\mathrm{LrCr}}}$

During the motoring and regenerating modes, the normalized motor currents are differently defined and expressed by (3)(4) and (5)-(6), respectively:

$\mathrm{I}_{\mathrm{N}}=\frac{\mathrm{V}_{\mathrm{g}}}{\mathrm{Z}}$

$\lambda=\frac{I_{0}}{I_{N}}$

$I_{N}=\frac{V_{0}}{Z}$

$\lambda=\frac{I_{g}}{I_{N}}$

The operating waveforms in the motoring mode are shown in Fig. 2, while the corresponding topological modes are illustrated in Fig. 3. Similarly, the operating waveforms in the regenerating mode are shown in Fig. 4, while the corresponding topological stages are illustrated in Fig. 5. As shown in Figs. 3 and 5, both modes exist seven operating stages within one switching cycle. 


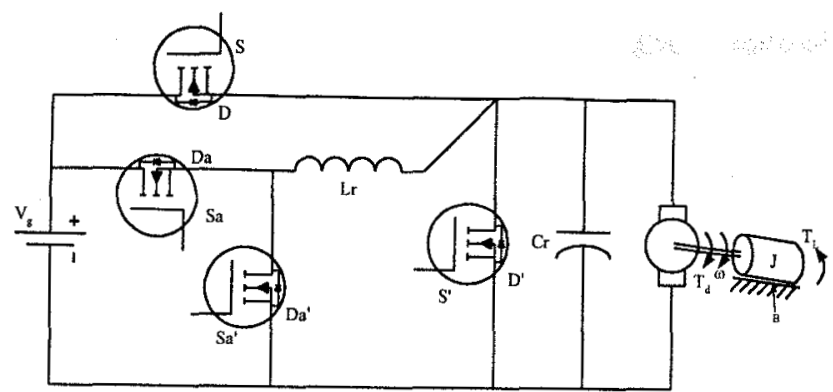

Fig. 1. Proposed ZVT-2Q converter.
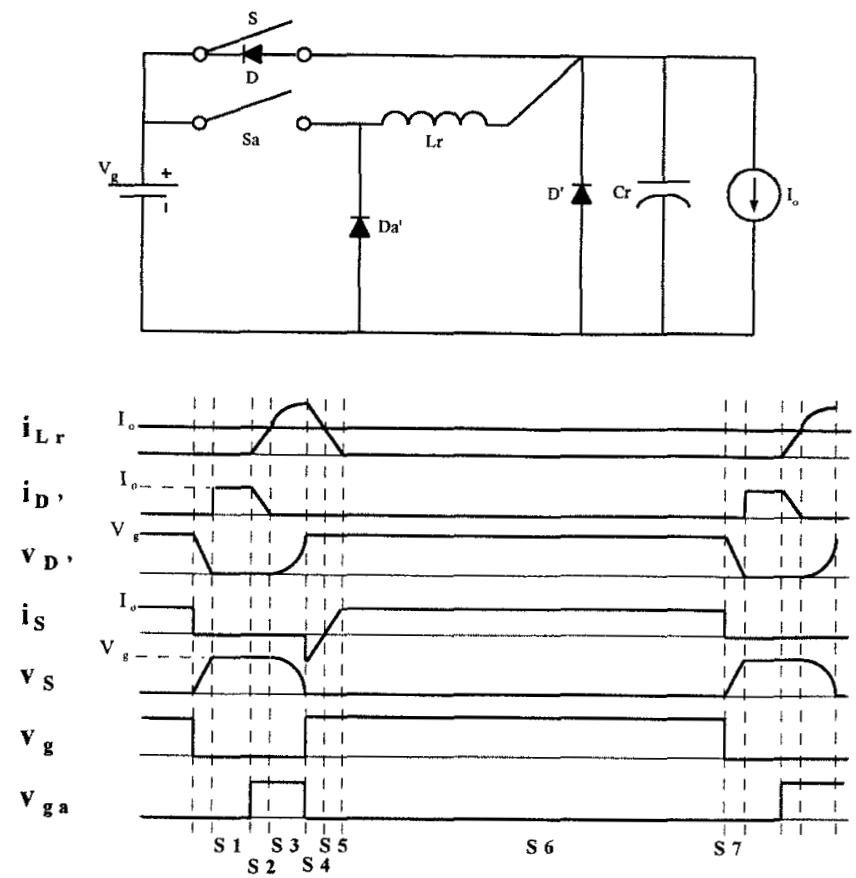

Fig. 2. Equivalent circuit and key waveforms during motoring mode.

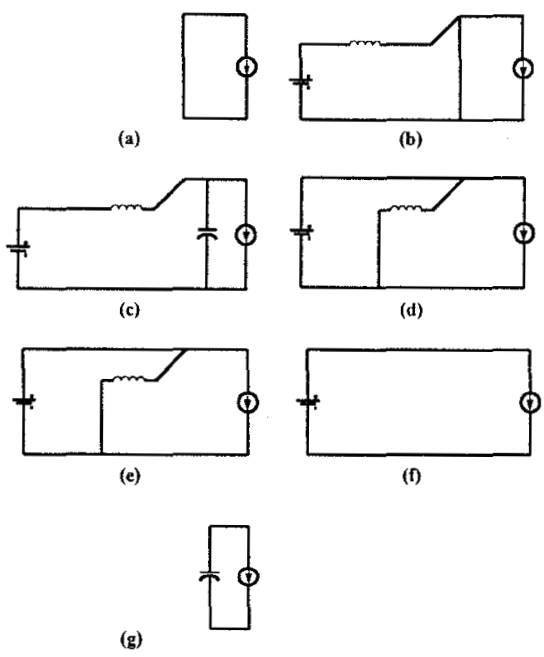

Fig. 3. Seven topological stages during motoring mode.
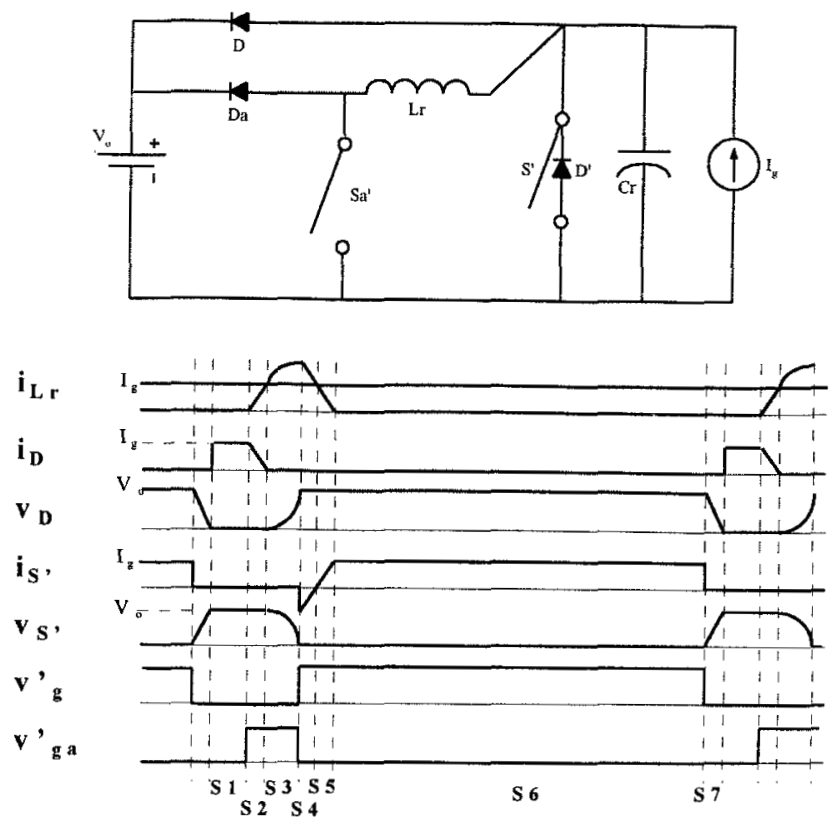

Fig. 4. Equivalent circuit and key waveforms during regenerating mode.

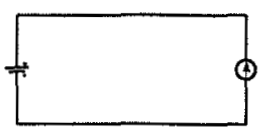

(a)

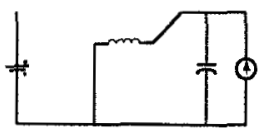

(c)

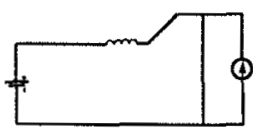

(e)

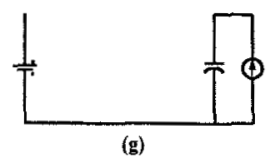

Fig. 5. Seven topological stages during regenerating mode.

\section{A. Motoring Mode (Figs. 2 \& 3)}

(a) Stage $1\left[T_{0}-T_{1}\right]$ : It is a freewheeling mode via $D^{\prime}$.

(b) Stage $2\left[T_{1}-T_{2}\right]: S_{a}$ is turned on. $i_{L r}$ increases according to the slope of $\mathrm{V}_{\mathrm{g}} / \mathrm{Lr}$, with zero initial conditions $\mathrm{i}_{\mathrm{Lr}}(0)=0$ and $\mathrm{v}_{\mathrm{D}^{\prime}}(0)=0$. $\mathrm{i}_{\mathrm{Lr}}$ can be expressed as:

$\mathrm{i}_{\mathrm{Lr}}(\mathrm{t})=\frac{\mathrm{V}_{\mathrm{g}}}{\mathrm{Lr}} \mathrm{t}$ 
This stage finishes at time $T_{2}$ when $\dot{i}_{L r}$ equals $I_{0}$. The duration can be determined from (7) as given by:

$\mathrm{T}_{2}=\frac{\mathrm{I}_{\mathrm{o}} \mathrm{Lr}}{\mathrm{V}_{\mathrm{g}}}$

(c) Stage $3\left[T_{2}-T_{3}\right]$ : When $i_{L r}=I_{o}, D^{\prime}$ is turned off with ZVS, and $\mathrm{Lr}$ and $\mathrm{Cr}$ start resonating. $\mathrm{i}_{\mathrm{Lr}}$ and $\mathrm{v}_{\mathrm{D}^{\prime}}$ are given by:

$\mathrm{i}_{\mathrm{Lr}}(\mathrm{t})=\mathrm{I}_{\mathrm{N}} \sin \omega \mathrm{t}+\mathrm{I}_{\mathrm{o}}$

$\mathrm{v}_{\mathrm{D}^{\prime}}(\mathrm{t})=\mathrm{V}_{\mathrm{g}}(1-\cos \omega \mathrm{t})$

$\mathrm{V}_{\mathrm{Cr}}$ or $\mathrm{V}_{\mathrm{D}^{\prime}}$ increases resonantly up to $\mathrm{V}_{\mathrm{g}}$ at $\mathrm{T}_{3}$ while $\mathrm{i}_{\mathrm{Lr}}=\mathrm{I}_{\mathrm{o}}+\mathrm{I}_{\mathrm{N}}$, and the duration can be determined by solving (10) as given by:

$\mathrm{T}_{3}=\frac{\pi}{2 \omega}$

(d) Stage $4\left[T_{3}-T_{4}\right]$ : When $v_{C r}$ or $v_{D^{\prime}}$ reaches $V_{g}, S$ is turned on with $Z V S . S_{a}$ is turned off to recover the stored energy in $\mathrm{Lr}$ to the source. Then $\mathrm{i}_{\mathrm{Lr}}$ flows through $\mathrm{D}_{\mathrm{a}}^{\prime}$ and decreases linearly with a slope of $V_{g} / L r . i_{L r}$ can be expressed as:

$\mathrm{i}_{\mathrm{Lr}}(\mathrm{t})=\mathrm{I}_{\mathrm{o}}+\mathrm{I}_{\mathrm{N}}-\frac{\mathrm{V}_{\mathrm{g}}}{\mathrm{Lr}} \mathrm{t}$

$\dot{\mathrm{I}}_{\mathrm{Lr}}$ decreases to $\mathrm{I}_{\mathrm{o}}$ at $\mathrm{T}_{4}$ and the duration can be determined from (12) as given by:

$\mathrm{T}_{4}=\frac{\mathrm{I}_{\mathrm{N}} \mathrm{Lr}}{\mathrm{V}_{\mathrm{g}}}$

(e) Stage $5\left[\mathrm{~T}_{4}-\mathrm{T}_{5}\right]$ : $\mathrm{i}_{\mathrm{Lr}}$ keeps decreasing while $\mathrm{i}_{\mathrm{S}}$ increasing until $i_{L r}$ reaches zero at $T_{5}$ and $D_{a}^{\prime}$ becomes off. During this stage, $i_{L r}$ is expressed as:

$$
\mathrm{i}_{\mathrm{Lr}}(\mathrm{t})=\mathrm{I}_{\mathrm{o}}-\frac{\mathrm{V}_{\mathrm{g}}}{\mathrm{Lr}} \mathrm{t}
$$

Since $i_{\mathrm{Lr}}$ decreases to zero at $T_{5}$, the duration can be determined by solving (14) which gives:

$\mathrm{T}_{5}=\frac{\mathrm{I}_{\mathrm{o}} \mathrm{Lr}}{\mathrm{V}_{\mathrm{g}}}$

(f) Stage $6\left[\mathrm{~T}_{5}-\mathrm{T}_{6}\right]$ : It is a powering mode.

(g) Stage $7\left[\mathrm{~T}_{6}-\mathrm{T}_{7}\right]$ : $\mathrm{I}_{\mathrm{o}}$ discharges $\mathrm{Cr}$ linearly with a slope of $\mathrm{I}_{\mathrm{o}} / \mathrm{Cr}$ until $\mathrm{V}_{\mathrm{D}}{ }^{\prime}$ equals zero at $\mathrm{T}_{7}$, and eventually $\mathrm{D}^{\prime}$ becomes conducting. During this stage, $v_{D}{ }^{\prime}$ can be expressed as:

$\mathrm{v}_{\mathrm{D}^{\prime}}(\mathrm{t})=\mathrm{V}_{\mathrm{g}}-\frac{\mathrm{I}_{\mathrm{o}} \mathrm{t}}{\mathrm{Cr}}$

Again, $T_{7}$ can be determined by solving (16), which gives:

$$
\mathrm{T}_{7}=\frac{\mathrm{V}_{\mathrm{g}} \mathrm{Cr}}{\mathrm{I}_{\mathrm{o}}}
$$

\section{B. Regenerating Mode (Figs. $4 \& 5$ )}

(a) Stage $1\left[\mathrm{~T}_{0}-\mathrm{T}_{1}\right]$ : $\mathrm{D}$ is conducting, a regenerating mode. (b) Stage $2\left[\mathrm{~T}_{1}-\mathrm{T}_{2}\right]: \mathrm{S}_{\mathrm{a}}{ }^{\prime}$ is turned on. $\mathrm{i}_{\mathrm{Lr}}$ increases with the slope of $V_{o} / L r$, while $i_{L r}(0)=0$ and $V_{D^{\prime}}(0)=V_{0}$. $i_{L r}$ can be expressed as:

$\mathrm{i}_{\mathrm{Lr}}(\mathrm{t})=\frac{\mathrm{V}_{0}}{\mathrm{Lr}} \mathrm{t}$

This stage finishes at time $T_{2}$ when $i_{L r}$ equals $I_{g}$. The duration can be determined using (18) and is given by:

$\mathrm{T}_{2}=\frac{\mathrm{I}_{\mathrm{g}} \mathrm{L}_{\mathrm{r}}}{\mathrm{V}_{\mathrm{o}}}$

(c) Stage $3\left[T_{2}-T_{3}\right]$ : When $i_{L r}$ reaches $I_{g}$ at $T_{2}, D$ is turned off with ZVS, and $\mathrm{Lr}$ and $\mathrm{Cr}$ start resonating. $\mathrm{i}_{\mathrm{Lr}}$ and $\mathrm{V}_{\mathrm{D}^{\prime}}$ are given by:

$$
\begin{aligned}
& i_{L r}(t)=\frac{V_{0}}{Z} \sin \omega t+I_{g} \\
& V_{D^{\prime}}(t)=V_{o} \cos \omega t
\end{aligned}
$$

$\mathrm{v}_{\mathrm{Cr}}$ or $\mathrm{v}_{\mathrm{D}^{\prime}}$ decreases to zero at $\mathrm{T}_{3}$, and the duration can be determined by solving (21) as given by:

$\mathrm{T}_{3}=\frac{\pi}{20}$

(d) Stage $4\left[T_{3}-T_{4}\right]$ : When $v_{S}$, reaches zero, $S^{\prime}$ is turned on with ZVS. $S_{a}{ }^{\prime}$ is turned off to recover the stored energy in Lr to the source. Then $i_{L r}$ flows through $D_{a}$ and decreases linearly, which can be expressed as:

$i_{L r}(t)=I_{g}+I_{N}-\frac{V_{o}}{L_{r}} t$

$i_{L r}$ decreased to $I_{g}$ at $T_{4}$ and the duration can be determined by solving (23) which gives:

$\mathrm{T}_{4}=\frac{\mathrm{I}_{\mathrm{N}} \mathrm{Lr}}{\mathrm{V}_{\mathrm{o}}}$

(e) Stage $5\left[T_{4}-T_{5}\right]: i_{L r}$ keeps decreasing and $i_{S}$ increasing until $i_{L r}$ reaches zero at $T_{5} . D_{a}$ becomes off. During this stage, $i_{L \Gamma}$ can be expresscd as:

$\mathrm{i}_{\mathrm{Lr}}(\mathrm{t})=\mathrm{I}_{\mathrm{g}}-\frac{\mathrm{V}_{\mathrm{o}}}{\mathrm{Lr}} \mathrm{t}$

$i_{\mathrm{Lr}}$ decrease to zero at $\mathrm{T}_{5}$ and the duration can be determined by solving (25) which gives:

$\mathrm{T}_{5}=\frac{\mathrm{I}_{\mathrm{g}} \mathrm{Lr}}{\mathrm{V}_{\mathrm{o}}}$

(f) Stage $6\left[\mathrm{~T}_{5}-\mathrm{T}_{6}\right]$ : It is a freewheeling mode.

(g) Stage $7\left[\mathrm{~T}_{6}-\mathrm{T}_{7}\right]$ : $\mathrm{I}_{\mathrm{g}}$ charges $\mathrm{Cr}$ linearly with a slope of $I_{g} / C r$ until $V_{D}^{\prime}$ equals $V_{o}$ at $T_{7}$, and eventually $D$ becomes conducting. During this stage, $v_{D}{ }^{\prime}$ can be expressed as:

$v_{D^{\prime}}(t)=V_{0}-\frac{I_{g} t}{C r}$

Again, $T_{7}$ can be determined by solving (27) and is given by:

$$
\mathrm{T}_{7}=\frac{\mathrm{V}_{\mathrm{o}} \mathrm{Cr}}{\mathrm{I}_{\mathrm{g}}}
$$




\section{CHARACTERISTICS CURVES}

\section{A. Motoring Mode}

The voltage-conversion ratio $\mu_{\mathrm{m}}$ in the motoring mode of operation can be derived by averaging $\mathrm{v}_{\mathrm{Cr}}$ or $\mathrm{v}_{\mathrm{D}}$.

For Stage 3, integrating (10) and using (11):

$\mathrm{v}_{\mathbf{D}^{\prime}}\left(\mathrm{T}_{3}\right)=\mathrm{V}_{\mathrm{g}}\left(\frac{\pi-2}{2 \omega}\right)$

For Stage 7, integrating (16) and using (17):

$\mathrm{v}_{\mathrm{D}^{\prime}}\left(\mathrm{T}_{7}\right)=\mathrm{V}_{\mathrm{g}}\left(\frac{\mathrm{V}_{\mathrm{g}} \mathrm{Cr}}{2 \mathrm{I}_{0}}\right)$

Also, we define the duty ratio $\delta_{\mathrm{m}}=\mathrm{T}_{4-6}$ and $\mathrm{T}_{3}$ as:

$\mathrm{T}_{3}=\frac{\mathrm{T}_{\mathrm{s}}}{\mathrm{x}}$

$\mathrm{T}_{s}=\frac{\mathrm{x} \pi}{2 \omega}$

where $T_{s}$ is the switching frequency.

Hence, by using (1), (3)-(4) and (29)-(32), the voltageconversion ratio $\mu_{\mathrm{m}}$ can be expressed as:

$\mu_{m}=\delta_{m}+\frac{\pi-2}{x \pi}+\frac{1}{x \pi \lambda}$

The corresponding results showing the voltage conversion ratio $\mu_{\mathrm{m}}$ versus load $\lambda$ and duty cycle $\delta_{\mathrm{m}}$ during the motoring mode are shown in Figs. 6 and 7, respectively.

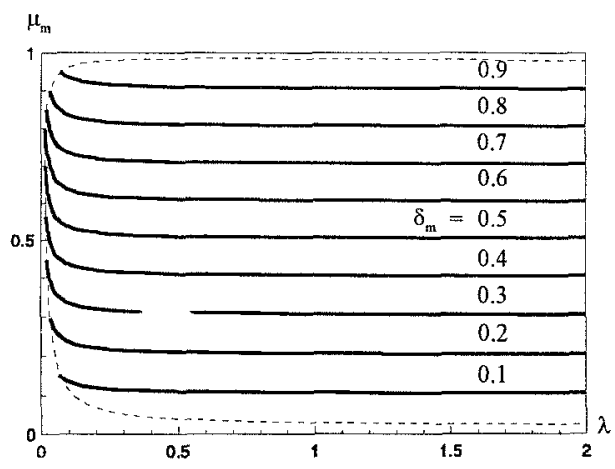

Fig. 6. Conversion ratio versus load at motoring $(x=100)$.

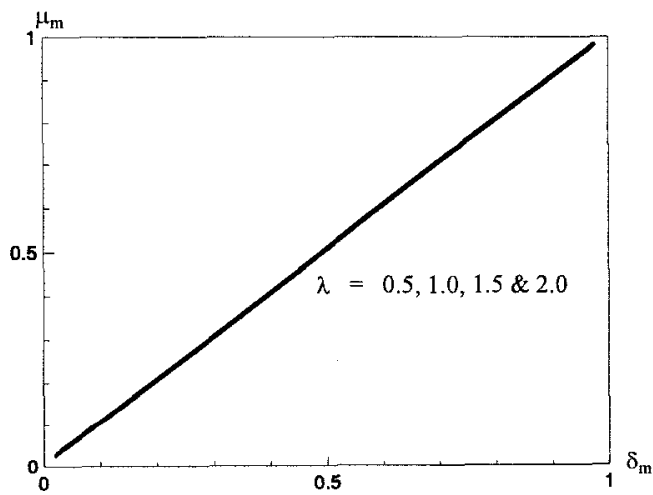

Fig. 7. Conversion ratio versus duty ratio at motoring $(x=100)$

\section{B. Regenerating Mode}

The voltage-conversion ratio $\mu_{\mathrm{r}}$ in the regenerating mode can be derived by equating the source energy per cycle $E_{s}$ and the output energy per cycle $\mathrm{E}_{\mathrm{o}}$ :

$\mathrm{E}_{\mathrm{s}}=\mathrm{V}_{\mathrm{s}} \mathrm{I}_{\mathrm{g}} \mathrm{T}_{\mathrm{s}}$

$\mathrm{E}_{\mathrm{o}}=\mathrm{V}_{\mathrm{o}}\left[\mathrm{i}_{\mathrm{D}}\left(\mathrm{T}_{1}\right)+\mathrm{i}_{\mathrm{D}}\left(\mathrm{T}_{2}\right)+\mathrm{i}_{\mathrm{Lr}}\left(\mathrm{T}_{4}\right)+\mathrm{i}_{\mathrm{Lr}}\left(\mathrm{T}_{5}\right)\right]$

For stage 2, from (18) and (19):

$\mathrm{i}_{\mathrm{D}}\left(\mathrm{T}_{2}\right)=\frac{\mathrm{I}_{\mathrm{g}}{ }^{2} \mathrm{Lr}}{2 \mathrm{~V}_{\mathrm{o}}}$

For Stage 4, from (23) and (24):

$\mathrm{i}_{\mathrm{Lr}}\left(\mathrm{T}_{4}\right)=\frac{\mathrm{I}_{\mathrm{g}} \mathrm{I}_{\mathrm{N}} \mathrm{Lr}}{\mathrm{V}_{\mathrm{o}}}+\frac{\mathrm{I}_{\mathrm{g}}{ }^{2} \mathrm{Lr}}{2 \mathrm{~V}_{0}}$

For stage 5, from (25) and (26):

$\mathrm{i}_{\mathrm{Lr}}\left(\mathrm{T}_{\mathrm{s}}\right)=\frac{\mathrm{I}_{\mathrm{g}}{ }^{2} \mathrm{Lr}}{2 \mathrm{~V}_{\mathrm{o}}}$

From (35) to (38):

$E_{o}=V_{o}\left[I_{g}\left(T_{1}\right)+\frac{I_{g}{ }^{2} L_{r}}{2 V_{o}}+\frac{I_{g} I_{N} L_{r}}{V_{o}}+\frac{I_{N}{ }^{2} L_{r}}{2 V_{o}}+\frac{I_{g}{ }^{2} L_{r}}{2 V_{o}}\right]$

By equating (34) and (39) and defining the duty ratio $\delta_{\mathrm{r}}=\mathrm{T}_{5-6}$ :

$\mu_{\mathrm{r}}=\frac{1}{1-\delta_{\mathrm{r}}-\frac{\pi-2}{\mathrm{x} \pi}-\frac{1}{\mathrm{x} \pi \lambda}}$

The corresponding results are shown in Figs. 8 and 9.

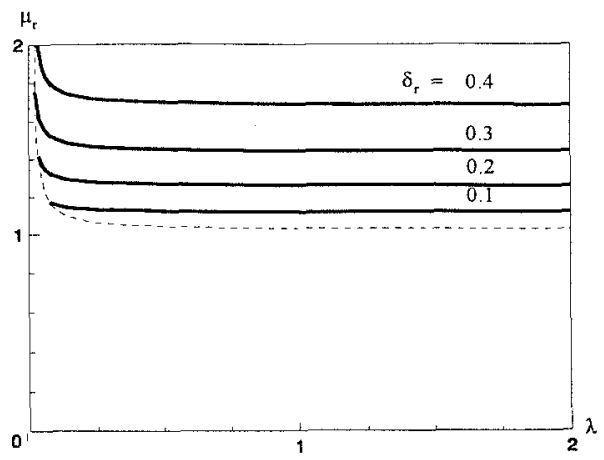

Fig. 8. Conversion ratio versus load at regenerating $(x=100)$.

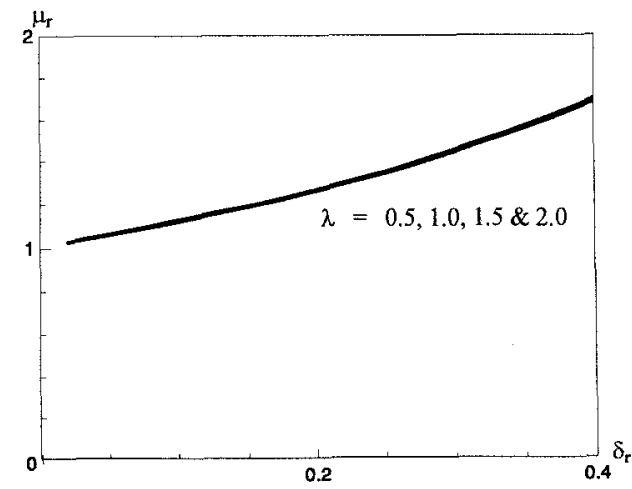

Fig. 9. Conversion ratio versus duty ratio at regenerating $(x=100)$ 
From (33) and (40), it can be shown that:

$$
\mu_{\mathrm{r}}=\frac{1}{1-\mu_{\mathrm{m}}}
$$

which is the same relation for conventional PWM buck and boost converters.

\section{DESIGN EXAMPLE}

In order to illustrate the design process, a design example of the proposed ZVT-2Q converter for dc motor drives is carried out. With the specifications $\mathrm{V}_{\mathrm{g}}=55-60 \mathrm{~V}, \mathrm{~V}_{0}=50 \mathrm{~V}, \mathrm{I}_{\mathrm{o}}=1-4 \mathrm{~A}$, $T_{s}=10 \mu \mathrm{s}, \mathrm{x}=100$, the values of $\mathrm{Lr}$ and $\mathrm{Cr}$ are selected such that the resonant peak current is about one-half of the maximum load current. Thus, $I_{N}=2$ A. From (1)-(3) and (32), we can deduce that $Z=30 \Omega, \omega=15.71 \times 10^{6} \mathrm{rad} / \mathrm{s}(2.5 \mathrm{MHz}), \mathrm{Cr}=2.12 \mathrm{nF}$ and $\mathrm{Lr}=1.91 \mu \mathrm{H}$.

\section{SIMULATION AND EXPERIMENTAL RESULTS}

To verify the theoretical results, the ZVT-2Q converter with the parameters obtained in the design example is PSpicesimulated and hardware prototyped. From simulation results shown in Figs. 10 and 11, main transistors ( $i_{S}, v_{S}$ in Fig. 10 and $i_{S^{\prime}}, v_{S^{\prime}}$ in Fig. 11) and rectifiers ( $i_{D}, v_{D^{\prime}}$ in Fig. 10 and $i_{D}, v_{D}$ in Fig. 11) operate with ZVS in both motoring and regenerating modes, and they are subjected to the same voltage and current stresses as those in the PWM counterpart. From the experimental waveforms shown in Figs. 12 and 13, they closely agree with those theoretical waveforms, especially the main switches ( $S$ and $D^{\prime}$ for motoring while $S^{\prime}$ and $D$ for regenerating) can always maintain ZVS operation. As shown in Figs. 14-17, the characteristics curves are verified for different voltage conversion ratios and loads. Moreover, as shown in Fig. 18, the measured efficiency $\eta$ of the proposed converter is quite high, ranging from $94 \%$ to $98 \%$.

\section{CONCLUSION}

A novel ZVT-2Q converter for dc motor drives has been presented. It possesses some definite advantages, including ZVS for all main switches and diodes, unity device voltage and current stresses, simple circuit topology and low cost, leading to achieve high switching frequency, high power density and high efficiency. Other key features are the use of the same resonant tank for both forward and backward power flows and the full utilization of all built-in diodes of the power switches, thus minimizing the overall hardware count and cost.

\section{ACKNOWLEDGMENT}

This work was supported and funded in part by the Committee on Research and Conference Grants, the University of Hong Kong.

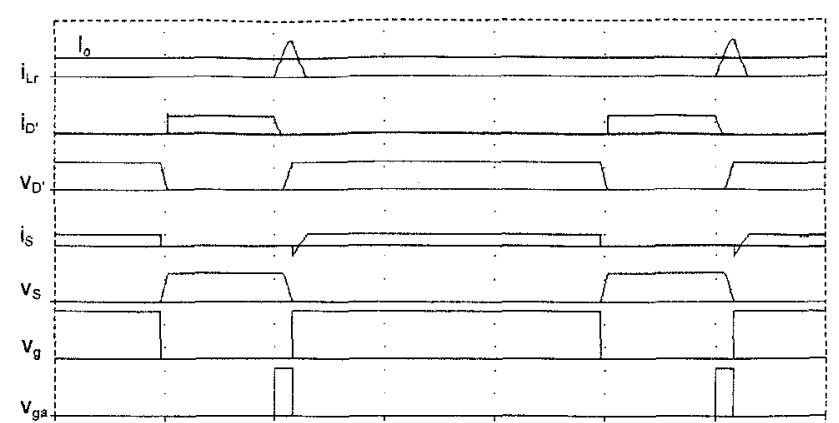

Fig. 10. PSpice simulation at motoring mode $\left(\delta_{\mathrm{m}}=0.7\right)$.

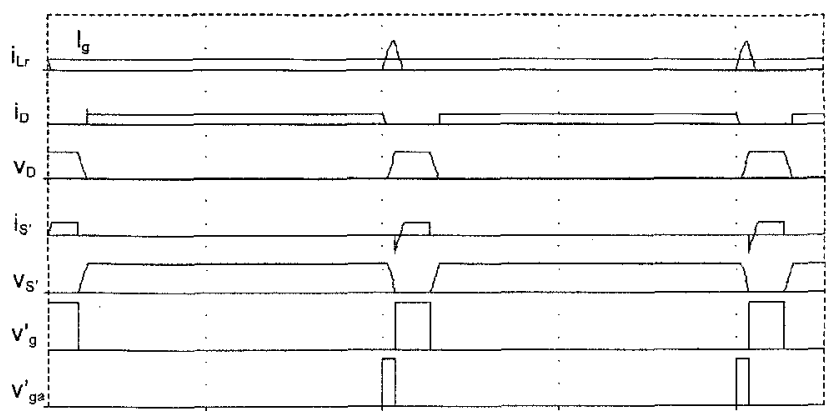

Fig. 1 1. PSpice simulation at regenerating mode $\left(\delta_{\mathrm{r}}=0.1\right)$.

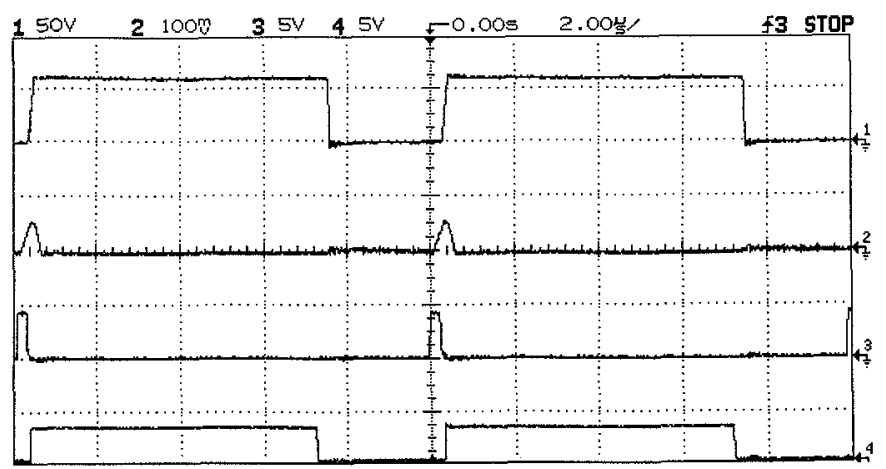

Fig. 12. Measured waveforms at motoring $\left(\delta_{\mathrm{m}}=0.7\right)$; $\mathrm{v}_{\mathrm{D}^{\prime}}(50 \mathrm{~V} / \mathrm{div}) ; \mathrm{i}_{\mathrm{Lr}}(10 \mathrm{~A} / \mathrm{div}), \mathrm{v}_{\mathrm{ga}}, \mathrm{v}_{\mathrm{g}}(5 \mathrm{~V} / \mathrm{div})$

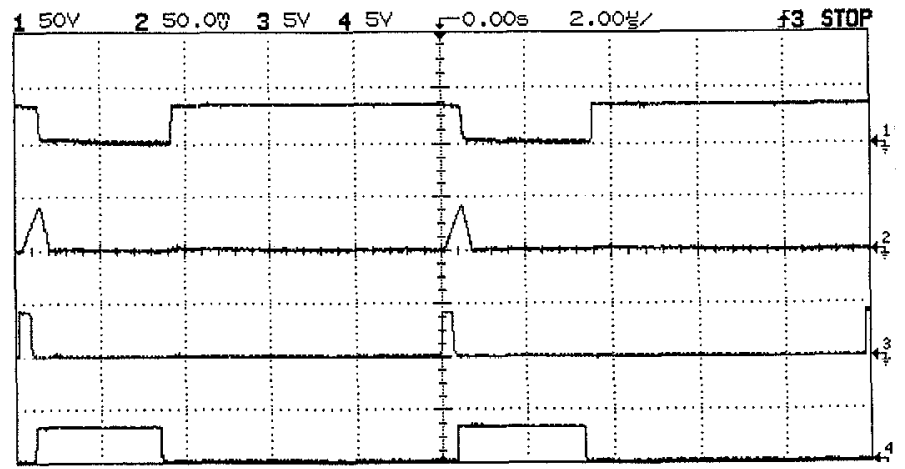

Fig. 13. Measured waveforms at regenerating $\left(\delta_{\mathrm{r}}=0.3\right)$; $\mathrm{v}_{\mathrm{S}^{\prime}}(50 \mathrm{~V} / \mathrm{div}) ; \mathrm{i}_{\mathrm{Lr}}(5 \mathrm{~A} / \mathrm{div}), \mathrm{v}_{\mathrm{ga}}{ }^{1}, \mathrm{v}_{\mathrm{g}}{ }^{\prime}(5 \mathrm{~V} / \mathrm{div})$. 


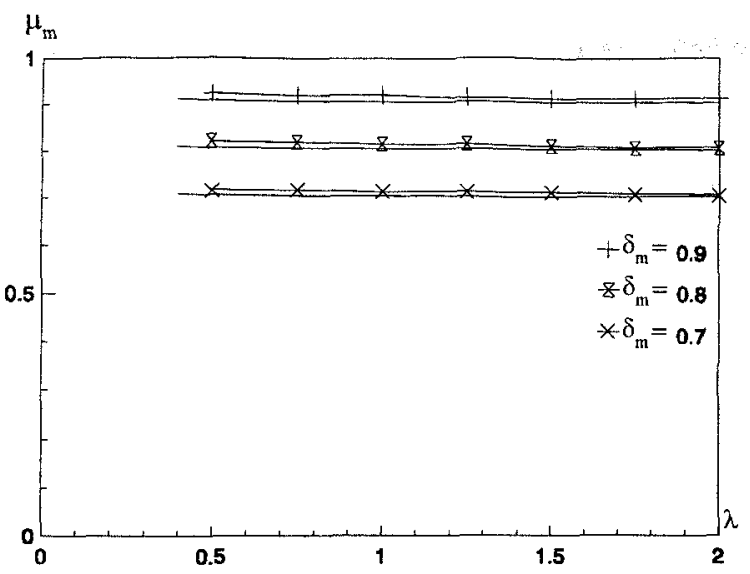

Fig. 14. Theoretical and experimental $\mu_{\mathrm{m}} \mathrm{vs} \lambda$ at motoring.

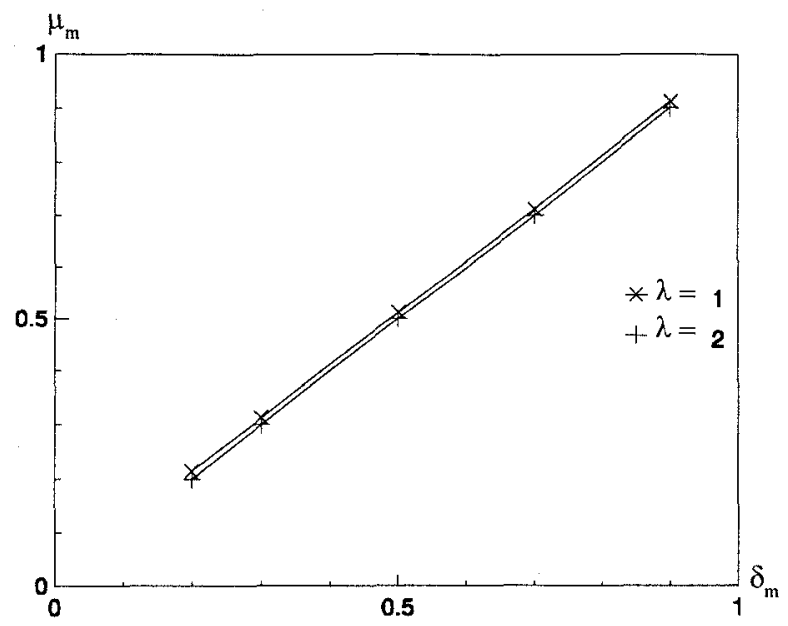

Fig. 15. Theoretical and experimental $\mu_{\mathrm{m}}$ vs $\delta_{\mathrm{m}}$ at motoring.

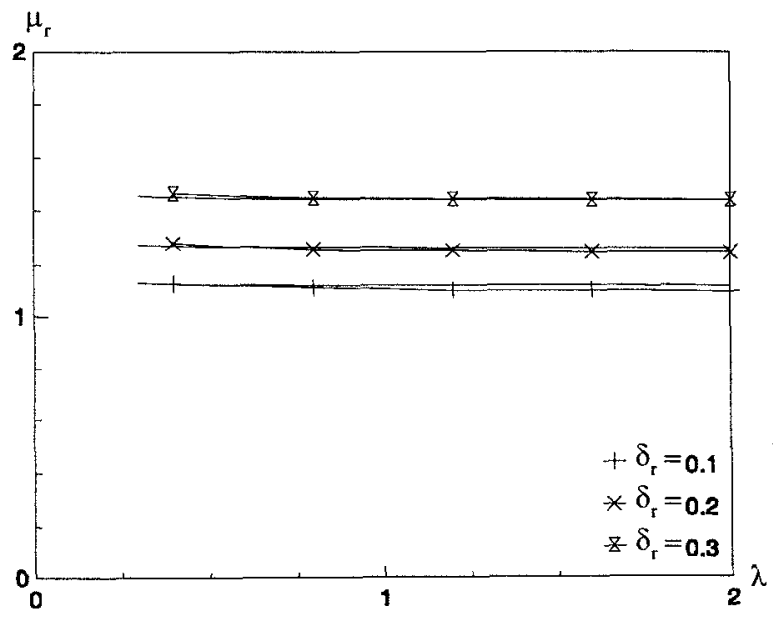

Fig. 16. Theoretical and experimental $\mu_{\mathrm{r}}$ vs $\lambda$ at regenerating.

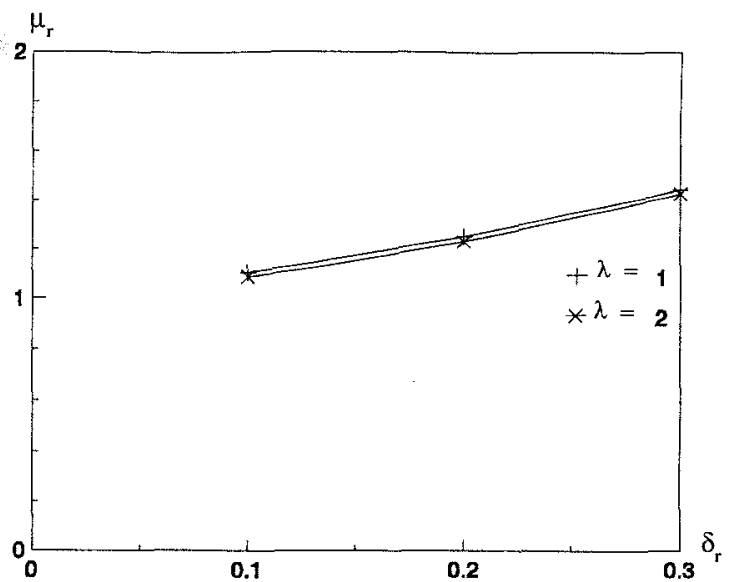

Fig. 17. Theoretical and experimental $\mu_{\mathrm{r}} v \mathrm{v} \delta_{\mathrm{r}}$ at regenerating.

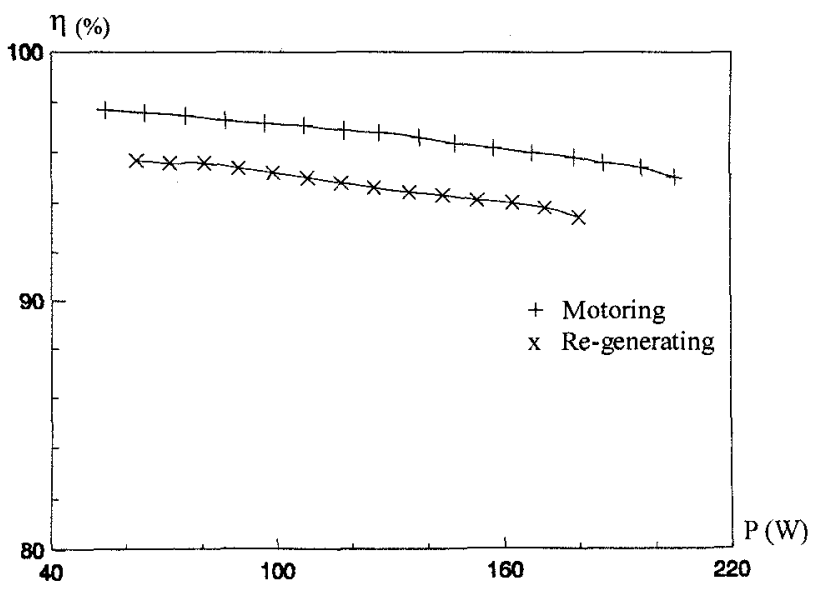

Fig. 18. Measured efficiency $\eta$ at both motoring and regenerating.

\section{REFERENCES}

[1] D. Maksimović and S. Cuk, "Constant-frequency control of quasi-resonant converters," IEEE Trans. Power Electron., vol. 6, 1991, pp. 141-150.

[2] C.C. Chan and K.T. Chau, "A new zero-voltageswitching dc/dc boost converter," IEEE Trans. Aero. Electron. Syst., vol. 29, 1993, pp. 125-134.

[3] G. Hua, C.S. Leu and F.C. Lee, "Novel zero-voltagetransition PWM converters," In Proceedings of VPEC Power Electronics Seminar, 1991, pp. 81-88.

[4] J.G. Cho, J.W. Baek, G.H. Rim and I. Kang, "Novel zero voltage transition PWM multi-phase converters," In Proceedings of IEEE APEC, 1996, pp. 500-506.

[5] C.C. Chong, C.Y. Chan and C.F. Foo, "A quasiresonant converter-fed dc drive system," In Proceedings of EPE, 1993, pp. 372-377.

[6] K.T. Chau, T.W. Ching and C.C. Chan, "Constantfrequency multi-resonant converter-fed $\mathrm{dc}$ motor drives," In Proceedings of IECON, 1996, pp. 78-83. 